\title{
The homing of bone marrow MSCs to non-osseous sites for ectopic bone formation induced by osteoinductive calcium phosphate
}

\author{
Guodong Song ${ }^{\mathrm{a}}$, Pamela Habibovic ${ }^{\mathrm{b}}$, Chongyun Bao ${ }^{\mathrm{a}, *}$, Jing $\mathrm{Hu}^{\mathrm{a}}$, Clemens A. van Blitterswijk ${ }^{\mathrm{b}}$, \\ Huipin Yuan ${ }^{\mathrm{b}}$, Wenchuan Chen ${ }^{\mathrm{a}, \mathrm{c}}$, Hockin H.K. Xu ${ }^{\mathrm{c}, *}$ \\ a State Key Laboratory of Oral Diseases, Sichuan University, Chengdu, China \\ ${ }^{\mathrm{b}}$ Department of Tissue Regeneration, MIRA Institute for Biomedical Technology and Technical Medicine, University of Twente, Enschede, The Netherlands

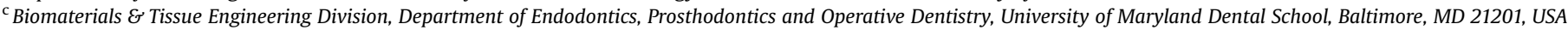

\section{A R T I C L E I N F O}

\section{Article history:}

Received 6 October 2012

Accepted 14 December 2012

Available online $\mathrm{xxx}$

\section{Keywords:}

Bone repair

Osteoinductive

Calcium phosphate ceramic

Bone marrow mesenchymal stem cells

Y chromosomes

Canine model

\begin{abstract}
A B S T R A C T
Osteoinductive biomaterials are promising for bone repair. There is no direct proof that bone marrow mesenchymal stem cells (BMSCs) home to non-osseous sites and participate in ectopic bone formation induced by osteoinductive bioceramics. The objective of this study was to use a sex-mismatched beagle dog model to investigate BMSC homing via blood circulation to participate in ectopic bone formation via osteoinductive biomaterial. BMSCs of male dogs were injected into female femoral marrow cavity. The survival and stable chimerism of donor BMSCs in recipients were confirmed with polymerase chain reaction (PCR) and fluorescence in situ hybridization (FISH). Biphasic calcium phosphate (BCP) granules were implanted in dorsal muscles of female dogs. Y chromosomes were detected in samples harvested from female dogs which had received male BMSCs. At 4 weeks, cells with Y-chromosomes were distributed in the new bone matrix throughout the BCP granule implant. At 6 weeks, cells with $\mathrm{Y}$ chromosomes were present in newly mineralized woven bone. TRAP positive osteoclast-like cells were observed in 4-week implants, and the number of such cells decreased from 4 to 6 weeks. These results show that osteoprogenitors were recruited from bone marrow and homed to ectopic site to serve as a cell source for calcium phosphate-induced bone formation. In conclusion, BMSCs were demonstrated to migrate from bone marrow through blood circulation to non-osseous bioceramic implant site to contribute to ectopic bone formation in a canine model. BCP induced new bone in muscles without growth factor delivery, showing excellent osteoinductivity that could be useful for bone tissue engineering.
\end{abstract}

(ㄷ) 2012 Elsevier Ltd. All rights reserved.

\section{Introduction}

Large-sized bulk bone defects resulting from tumor, trauma and congenital deformity have constituted a challenging problem in orthopedic surgery [1-6]. Health care costs plus the lost wages for people with musculoskeletal diseases reached approximately $\$ 849$ billion in 2004 in the USA, or 7.7\% of the national gross domestic product [7]. Although therapies of autograft and allograft transplantation have been used in clinical procedures, the treatments have disadvantages including donor site morbidity, harvesting limitation, and risks of disease transmission. Therefore, methods exploiting osteoinductive biomaterials to repair large-sized defects

\footnotetext{
* Corresponding authors.

E-mail addresses: cybao9933@scu.edu.cn (C. Bao), hxu@umaryland.edu (H.H.K. Xu).
}

provide a promising alternative. The osteoconductive properties of biomaterials could enhance bone healing [8-10]. Furthermore, the development and use of osteoinductive biomaterials could play an important role in bone regeneration [11-14].

Calcium phosphate bioceramics are important for hard tissue repair because of their excellent biocompatibility and chemical similarity to the minerals in bones [15-21]. Calcium phosphate implants possess osteoconductivity and bioactivity to form a functional interface with neighboring bone [22-25]. After the first report in 1969 [26], several studies have demonstrated that osteoinductive biomaterials, including hydroxyapatite (HA), biphasic calcium phosphate (BCP), and $\beta$-tricalcium phosphate (TCP), can induce new bone formation in non-osseous sites of large animals without the delivery of cells or growth factors [11,27,28]. In vivo studies suggested that the osteoinduction was not closely related to the chemistry of the materials $[25,29]$. Instead, the physical morphology of the biomaterial, including its macroporous 
structure and microporous surface, appeared to be critical to osteoinduction and ectopic bone formation $[25,29]$. In addition, the intriguing biological phenomenon of osteoinduction via biomaterials alone without delivering cells/growth factors has only been observed in non-osseous sites of large animals such as dogs, goats and baboons, and has not been observed in rodents [11,12]. Regarding the mechanism of osteoinduction by biomaterials, it was hypothesized that biomaterials in vivo could adsorb endogenous growth factors from the body fluids, which in turn would facilitate the recruitment and homing of relevant pluripotent stem cells to form new bone [30]. However, there is no evidence to prove this mechanism. In particular, there is no direct proof that mesenchymal stem cells (MSCs) in the animal's bone marrow home to the non-osseous site and participate in ectopic bone formation induced by osteoinductive bioceramics.

Tissue engineering offers immense promise to millions of patients suffering from debilitating diseases $[3,4,31]$. Stem cells guided for osteogenic differentiation and delivered via various scaffolds have the potential to meet the increasing need for bone regeneration [22,31-36]. Bone marrow-derived MSCs as a multipotent cell population can differentiate into several special cell types, including bone, muscle, cartilage and fat cells. Studies have shown that when an organ or tissue suffered from pathological injury, the BMSCs could be mobilized from remote bone marrow and recruited to home to the injured site to repair the tissue by differentiating into specified cell types in the lesion site $[37,38]$. Therefore, the present study investigated whether BMSCs from the animal's bone marrow could migrate to the implant site by blood circulation to participate in ectopic bone formation.

The objective of the present study was to use a sex-mismatched beagle dog model to investigate the homing of BMSCs via blood circulation to participate in ectopic bone formation via osteoinductive biomaterial. BMSCs of the male dog were injected into the bone marrow of a matching female dog recipient. The sex mismatch model is used to investigate the male's BMSC migration to the osteoinductive biomaterial implant site in the female to participate in ectopic bone formation, using $\mathrm{Y}$ chromosomes to track cell origin. It was hypothesized that: (1) The male donor BMSCs injected into the bone marrow cavity of female recipient would obtain stable chimerism and would successfully home to the female's defect site; (2) There would be successful ectopic new bone formation in the muscles of the female dog, and Y chromosomes would be detected in the new bone. It is anticipated that these results will facilitate the understanding of the mechanisms of BMSC migration from bone marrow and participation in ectopic bone formation via osteoinductive biomaterials.

\section{Materials and methods}

\subsection{Experimental animals and calcium phosphate biomaterial}

Adult male and female mixed breed littermate beagle dogs (3-4 years old, 8.5$10 \mathrm{~kg}$ ) which had been vaccinated for canine distemper, parainfluenza, adenovirus, leptospirosis, parvovirus, were used in the present study. All animals (seven male dogs, and eight female dogs) were housed in the Association for Accreditation of Laboratory Animal Care accredited facilities. The experimental protocol was approved by the Animal Care and Use Committee of Sichuan University and followed $\mathrm{NIH}$ guidelines. With the use of highly polymorphic major histocompatability complex classland classII microsatellite markers $[39,40]$ on the seven male and eight female dogs, four littermate donor/recipient pairs were matched. The BCP ceramic was made by a chemical precipitation method (Xpand Biotechnology BV, Bilthoven, Netherlands) with a HA/ $\beta$-TCP ratio of $5 / 1$. The ceramic was sintered at a temperature of $1150{ }^{\circ} \mathrm{C}$. BCP particles with sizes ranging from approximately $100-200 \mu \mathrm{m}$ were prepared, cleaned with $75 \%$ alcohol, dried and sterilized with high pressure steam. The chemical purity of the BCP powder was analyzed by X-ray diffraction (XRD, Philips Analytic, CuKa source). The BCP surface microstructure was examined with Scanning electron microscopy (SEM, JSM-7001F, Japan). The pore size, pore size distribution, and pore volume fraction of BCP were evaluated with mercury intrusion (AutoPore IV 9500, Micromeritics GmbH, Germany). The specific surface area of
BCP was analyzed by multipoint-BET (AUTOSORB-1, Quantachrome Instruments, Boynton Beach, FL, USA).

\subsection{Culture of BMSCs from male donors}

BMSCs were harvested from male dogs and cultured using a modified method as described previously [41,42]. After intravenous anesthesia with $3 \%$ sodium pentobarbital ( $1 \mathrm{~mL} / \mathrm{kg}$ ), $5 \mathrm{~mL}$ of bone marrow (BM) aspirates were collected from the iliac crests of male dogs and transferred to a pre-heparinized centrifuge tube. Mononuclear cells were separated by percoll $(1.073 \mathrm{~g} / \mathrm{mL}$, Sigma, St. Louis, MO) gradient centrifugation and then plated in $100 \mathrm{~mm}$ dishes at a density of $1 \times 10^{5}$ cells $/ \mathrm{cm}^{2}$. Cells were cultured in growth medium consisting of $\alpha$-MEM (Gibco, Grand Island, NY) supplemented with $10 \%$ fetal bovine serum (FBS, Gibco), $2 \mathrm{mM}$ L-glutamine (Sigma), $100 \mathrm{U} / \mathrm{mL}$ penicillin, $100 \mu \mathrm{g} / \mathrm{mL}$ streptomycin sulfate at $37{ }^{\circ} \mathrm{C}$ with $5 \%$ $\mathrm{CO}_{2}$. The medium was changed after $48 \mathrm{~h}$ and then every $3 \mathrm{~d}$. When the cells reached 80-90\% confluence, they were detached with $0.25 \%$ trypsin/EDTA (Gibco), subcultured at a density of $1 \times 10^{5}$ cells $/ \mathrm{cm}^{2}$ in $100 \mathrm{~mm}$ dishes. BMSCs of the third passage were used in the present study.

\subsection{Animal model on sex-mismatched allogeneic transplantation of BMSCS}

Total body irradiation (TBI) was performed to achieve immunosuppression in the female dogs to make sure that there was no immune rejection of the male BMSCs, following previous studies $[43,44]$. The four matching female dogs were given a single dose of 100 cGy TBI by a 6-million electron volt (Mev) linear accelerator at a rate of $28.5 \mathrm{cGy} / \mathrm{min}$ prior to transplantation. Within $8 \mathrm{~h}$ after TBI, BMSCs from littermate male donor at a dose of $4 \times 10^{8}$ cells $/ \mathrm{kg}$ were engrafted into the matching female dog recipient by IO injection using a previously established method [45]. Briefly, after the female recipient dog was successfully anesthetized, two needles were inserted into the proximal and distal parts of the right femur. A syringe containing $15 \mathrm{~mL}$ of heparinized saline was connected to one needle, and an empty syringe was connected to the other needle. The plunger of the empty syringe was pulled to harvest the BM, and the saline in the other syringe was consequently aspirated into the bone marrow cavity. Twenty milliliters of saline-bone marrow mixture was drawn out of the bone marrow cavity without any increase in marrow cavity pressure. BMSCs in volume of $2 \mathrm{~mL}$ were then injected into the marrow cavity through one needle, while applying gentle suction through a syringe attached to the other needle. Gentle syringe suction/pressure was then applied until the $2 \mathrm{~mL}$ BMSC solution was fully injected into the female marrow cavity. The needle hole was sealed with bone wax. All recipients were given standard post-grafting care consisting of cyclosporine (CSP, Zhejiang Ruibang, China) $15 \mathrm{mg} / \mathrm{kg}$ twice daily orally from 1 to $35 \mathrm{~d}$, and mycophenolate mofetil (MMF, Hainan Chuntch, China) $10 \mathrm{mg} / \mathrm{kg}$ twice daily subcutaneously from 1 to $27 \mathrm{~d}[43,44]$. The other four female dogs, which did not receive BMSC transplantation but accepted the same irradiation and treatments, served as control.

\subsection{Chimerism analysis of transplanted BMSCs in recipients}

To confirm that the male donor BMSCs in the bone marrow of female recipients acquired stable chimerism and exerted autospecific function, bone marrow aspirate was collected from the left femur at $7 \mathrm{~d}$ after the BMSC infusion (which was performed in the right femur). The cells were harvested and cultured in vitro as described above, to obtain the first passage of BMSCs. The BMSCs were further expanded and cells of passage three were used for PCR analysis. In addition, the BMSCs were seeded at a density of $2 \times 10^{4} / \mathrm{mL}$ on coverglass and cultured for $4 \mathrm{~d}$ to be used in the FISH test, as described below.

\subsection{Surgical procedures for BCP bioceramic implantation}

BCP bioceramic implantation was performed in all female dogs at $14 \mathrm{~d}$ after BMSC injection. Under general anesthesia through intramuscular injection of ketamine $(10 \mathrm{mg} / \mathrm{kg})$, the lumber area was shaved, disinfected and prepared for surgery. A midline skin incision of $10 \mathrm{~cm}$ was made on the back and dorsal muscle was exposed. Small pockets ( 6 independent sites per animal) were created with blunt dissection, and $500 \mathrm{mg}$ of BCP granules were placed into the muscle punches and sealed with silk suture. The wound was closed in layer with sutures. The surgical procedure was performed according to the standard surgical techniques. Standard postoperative care included monitoring the temperature, pulse and respiration, and administration of intravenous nutrition and antibiotics. All eight female dogs received BCP implants (4 donor BMSC recipient dogs, and 4 dogs of the control group).

The implants were harvested at 4 weeks ( 2 donor BMSC recipients, and 2 dogs of the control group) and 6 weeks ( 2 donor BMSC recipients, and 2 dogs of the control group) by an overdose of anesthetics ( $3 \%$ pentobarbital sodium). Because there were six implants per dog, this yielded 12 implants for donor BMSC recipient dogs, and 12 implants for control dogs, at each time period. All dissected samples were divided into two groups. One group with surrounding tissues was placed into $4 \%$ paraformaldehyde fixative for histological evaluation. The other group in which all soft 
tissue was fully removed was immediately placed in liquid nitrogen for PCR detection.

\subsection{Histological analysis}

The samples fixed in paraformaldehyde were decalcified in $15 \%$ formic acid in PBS for 4-7 weeks, and then embedded in paraffin. Thin sections of $5 \mu \mathrm{m}$ thickness were obtained and stained for hematoxylin and eosin (H\&E) and Masson staining. Additional sections were used for immunohistochemical staining and FISH test after deparaffinization and rehydration. Histological images were obtained using a Leica DFC 490 microscope (Leica, Switzerland). Neovascularization and multinucleated cell numbers were assessed in the sections by two veteran pathologists using singleblind counting under light microscopy. The densities of blood vessel capillary and multinucleated cells (per $\mathrm{mm}^{2}$ ) were measured.

2.7. Immunohistochemistry of collagen I and tartrate-resistant acid phosphatase (TRAP)

Immunohistochemistry analysis of the a2 subunit of collagen I was performed. The 5- $\mu \mathrm{m}$ deparaffinized sections on slides were rehydrated, incubated with $3 \%$ hydrogen peroxide, and then boiled in sodium citrate buffer for $10 \mathrm{~min}$. After cooled at $4{ }^{\circ} \mathrm{C}$ for $20 \mathrm{~min}$, the slides were blocked for $15 \mathrm{~min}$ with $1.5 \%$ horse serum. Subsequently, rabbit anti-human collagen I polyclonal antibody (Sigma) at a 1:500 dilution was dropped onto the slides which were incubated for $15 \mathrm{~min}$ with a 1:200 dilution of biotinylated goat anti-mouse IgG (Invitrogen, Carlsbad, CA). The slides were incubated for $15 \mathrm{~min}$ in $37^{\circ} \mathrm{C}$ with avidin horseradish peroxidase, followed by 1 min staining with 3,3'-Diaminobenzidine (DAB) and nuclear counterstaining with hematoxylin. Serial sections stained with phosphate buffered saline were used as negative controls.

TRAP is highly expressed by osteoclasts and therefore can be used to stain these cells. TRAP staining was performed using the TRAP Kit KT-008 (Kamiya, USA) following the manufacturer's instructions. Briefly, with a mixture of $15 \mathrm{mg}$ of red violet LB salt, $3 \mathrm{mg}$ of naphthol AS-BI phosphate, $2.4 \mathrm{mM} \mathrm{L}(+)$-tartaric acid diluted in $0.1 \mathrm{M}$ sodium acetate buffer ( $\mathrm{pH}$ 5.3), the deparaffinized sections were incubated for $30 \mathrm{~min}$ at $60^{\circ} \mathrm{C}$ and then counterstained with methyl green. TRAP positive cells appeared in a dark brown color, and the nuclei appeared in green.

\subsection{Fluorescence in situ hybridization (FISH) detection}

FISH can specifically detect DNA or RNA in situ and find where the target DNA or RNA is located. FISH was carried out using a SRY BIOISH hybridization kit (Tianjin Haoyang Manufacture, China). Both in vivo samples in decalcified sections and in vitro cells cultured on coverslips were tested after fixation, following the manufacturer's instructions. Six sections per dog (with one section per implant harvested from the six implants in each dog) were used in the FISH test. The sections were deparaffininized and rehydrated with xylene and graded ethanol solutions. Specific canis SRY probes (5'-GTC TCT ACC GTT TCC TCC GCT TTC ACA 5'-GCT GAT CTC TGA GTT TTG CAT TTG GGG A, 5'-GGT ATT TCT CTC GGT GCA TGG CCT GTA) were labeled with biotin-16-dUTP. The slides were placed in TBS ( $\mathrm{pH} 8.9$ ) solution and the DNA denaturation was performed at a temperature of $100{ }^{\circ} \mathrm{C}$ for 20 min by dropping the slides into boiling TBS. They were then incubated overnight with hybridization mixture at $37^{\circ} \mathrm{C}$. After several washes, the bound probes were detected with avidin-fluorescein isothiocyanate (FITC), and the nuclei were counterstained with DAPI. The specimens were examined in an epifluorescence microscope (Carl Zeiss, Oberkochen, Germany) coupled to a FISH-2.0 software imaging system.

\subsection{DNA extraction and polymerase chain reaction (PCR)}

Universal Genomic DNA Extraction kit Ver.3.0 (Takara, Japan) was used to extract the DNA from the in vivo implants, as well as from the cells of the bone marrow aspirate from the left femur. Frozen in vivo samples were ground in mortar with liquid nitrogen, and the DNA of in vivo implants was obtained with $50 \mathrm{mg}$ tissues. The DNA for the cells was obtained from $1.8 \times 10^{7}$ cells. After being eluted from spin column using $200 \mu \mathrm{L}$ Tris-EDTA buffer ( $1 \mathrm{mM}$ EDTA, $10 \mathrm{Mm}$ Tris- $\mathrm{HCl}, \mathrm{pH} 8)$, the DNA was stored at $-20^{\circ} \mathrm{C}$ to prevent acid hydrolysis. The DNA concentrations were measured by spectrophotometry.

Primers for the Y-chromosome marker (Canis SRY - specific oligonucleotide primers: $5^{\prime}$ - TGG TGT GGT CTC GCG ATC AAA G, 5' - CTG CGC CTC CTC GAA GAA TGG) and GAPDH marker (canis GAPDH marker gene oligonucletide primers: $5^{\prime}$ - GCT CCT TCT GCT GAT GCC CCC A, 5' - TGG GTG GCA GTG ATG GCA TGG) $[46,47]$ were synthesized by suppliers (Takara Biotechnology, Dalian, China). The PCR mixture contained $2.5 \mathrm{ng}$ of genomic DNA, $20 \mu \mathrm{M}$ of each primer, $25 \mathrm{mM}$ of $\mathrm{MgCl}_{2} 1.25 \mathrm{U}$ of Taq polymerase, and PCR and sterile water in a final volume of $50 \mu \mathrm{L}$. The PCR was conducted in a thermal cycler (Esco, Singapore) by 30 cycles of denaturation $\left(0.5 \mathrm{~min}, 94^{\circ} \mathrm{C}\right)$, annealing $\left(1 \mathrm{~min}, 58^{\circ} \mathrm{C}\right)$, and followed by extension $\left(1 \mathrm{~min}, 72{ }^{\circ} \mathrm{C}\right)$. Each PCR product was analyzed in parallel with 25 base pair ladder markers on $2 \%$ ethidium bromide-stained agarose gel, and exposed to UV light

\subsection{Statistical analysis}

All quantitative data were analyzed with SPSS 11.5 (SPSS Inc., Chicago, IL). The Fischer exact test was used for statistical analysis. A difference in values with $p<0.05$ was considered statistically significant.

\section{Results}

Fig. 1 shows (A, B) representative SEM images, and (C) X-ray diffraction, of BCP granules. BCP granules are shown in (A) at a low magnification, with irregular shapes and sizes of approximately $100-200 \mu \mathrm{m}$. A higher magnification is shown in (B) for a single granule, revealing a microstructure which consisted of numerous micron-sized crystalline grains being fused together, having micropores of about $0.5-2 \mu \mathrm{m}$ which were interconnected within the granule. In (C), the $\mathrm{x}$-ray diffraction pattern of the granules showed peaks corresponding to $\mathrm{BCP}$, allowing the two phases (HA and $\beta$-TCP) of this calcium phosphate to be clearly identified. Based on the comparison to the XRD patterns of HA and $\beta$-TCP, the BCP contained HA and $\beta$-TCP, and there were no other phases present. Based on the XRD patterns recorded, quantitatively (mean $\pm \mathrm{sd}$; $n=4)$, BCP contained ( $79 \pm 1) \%$ of HA, and $(21 \pm 1) \%$ of $\beta$-TCP by weight, as calculated from a calibration curve using mixtures with various predetermined HA/ $\beta$-TCP ratios. The BCP particles contained both large pores and small pores, with a total pore volume fraction of $(64 \pm 3) \%$. The macroporosity (with pore sizes between $10 \mu \mathrm{m}$ and $600 \mu \mathrm{m}$ ) was $34 \%$, the microporosity (with pore sizes between $1 \mu \mathrm{m}$ and $10 \mu \mathrm{m}$ ) was $1 \%$, and the nanoporosity (with pore sizes smaller than $1 \mu \mathrm{m}$ ) was $29 \%$. The specific surface area of BCP was $(1.49 \pm 0.10) \mathrm{m}^{2} / \mathrm{g}$.

Within 1 week of BMSC transplantation, all animals suffered from a series of feeble complications related to irradiation, including of a depressed spirit, anepithymia and oliguria. Subsequently, they recovered well and maintained good health throughout this study. Four and six weeks after implantation, the ceramic granules formed a rigid mass attached to the surrounding tissues. Inflammation, infection and tissue necrosis in the implanted sites were not observed. Macroscopically, the implants demonstrated a cohesive structure with BCP granules firmly bound to each other via the newly-formed tissues, and no loose BCP granules were noted in the implantation sites.

Donor BMSC homing in the bone marrow of dogs was evaluated by analyzing, in the left femur, the presence of donor BMSCs which had been transplanted into the right femur. As seen in Fig. 2A, after 30 cycles, SRY band and GAPDH band were clearly exhibited on agarose gels. The FISH method was used to further assess the donor BMSC homing in bone marrow after IO infusion. As shown in the epifluorescence microscopic images in Fig. 2B-G, the $Y$ chromosome-specific FITC signal (green) was noted inside the nuclei of BMSCs (Fig. 2B and D). The FISH method in (B) used the FITC dye which stained the Y chromosomes in green. There was one $\mathrm{Y}$ chromosome inside a single BMSC. FITC could also nonspecifically bind with cytoplasm, hence the cytoplasm also showed a green color. The FISH method in (C) used the DAPI dye which was specific for nucleus and stained the nuclei in blue color. Image (D) was merged from (B) and (C). In (E-G), the green color for the cytoplasm was filtered out to show the presence of the $Y$ chromosomes as bright dots (arrows). These results indicate that the animal experiment on sex-mismatched allogeneic BMSC transplantation was successful, and a studying platform to trace BMSCs was established. These results indicate that donor BMSCs could migrate through blood circulation into remote tissues (from right to left femur in this example) to exert autospecific function.

Four week after implantation, all implants were colonized with abundant cancellated constructions in contact with the ceramic in 

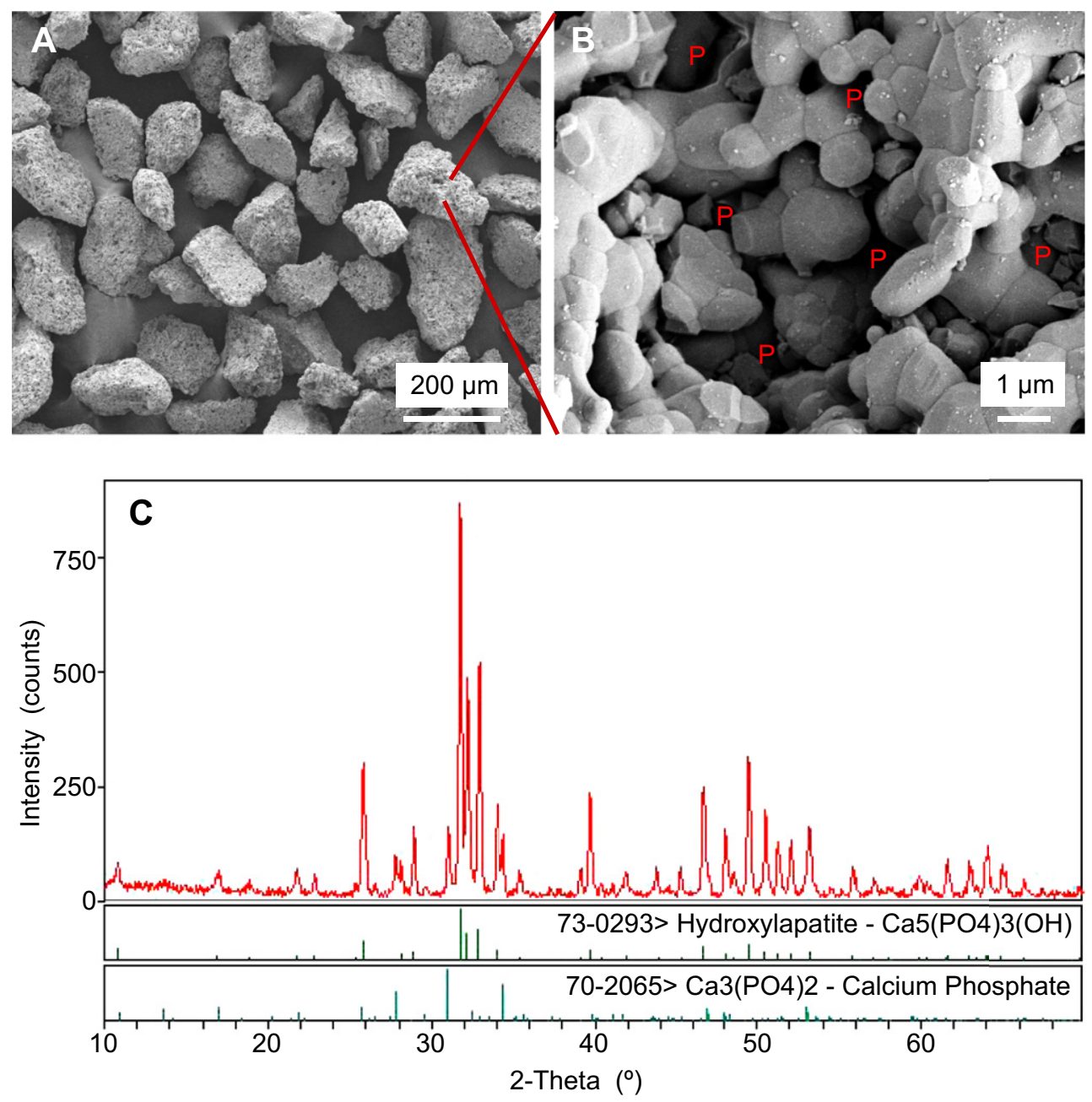

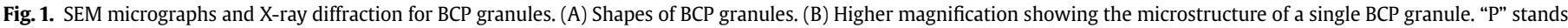
for pores. (C) X-ray diffraction pattern of the BCP granules.

the intergranular spaces. Fig. 3A showed numerous clonal monocytoid cells (examples were indicated by the small circles) in the middle region in between the $\mathrm{BCP}$ particles. These regions stained red in $\mathrm{H} \& \mathrm{E}(\mathrm{A})$, and blue in Masson (B), indicating the existence of a new bone matrix. Some of these monocytoid cells were likely preosteoblasts. No bone trabecular was found at 4 weeks, and the red area in (A) was non-mineralized bone, as numerous cells were found in it. On the periphery of the BCP particles, multinucleated cells adhered to the BCP granules. Examples of the multinucleated cells are enclosed by the green lines, showing a typical multinucleated osteoclast feature with a ruffled border facing the $\mathrm{BCP}$ particle.

After 6 weeks of implantation in Fig. 4, bone formation was clear with the signs of active cubic osteoblasts (indicated by arrows) which formed columnar layers on the surfaces of the BCP particles. Osteoblasts were located at the boundary of the advancing new bone matrix. Osteocytes were embedded in the mineralized bone matrix. The bone matrix was shown by the $\mathrm{H} \& \mathrm{E}$ staining in $(\mathrm{A})$ which stained the bone matrix collagen into red, and by the Masson staining in (B) which stained the collagen into blue. Mineralized bone is usually identified by the presence of osteocytes which are encapsulated in the bone matrix.

The new bone matrix area fraction was estimated as the new bone area in the image divided by the total area of the image. The new bone matrix area fraction was measured to be $(65 \pm 13) \%$ at 6 weeks, significantly higher than $(42 \pm 12) \%$ at 4 weeks $(p<0.05)$.
In addition, examples of new blood vessels and blood cells are indicated in the lower part of Fig. 4B. They appeared to be vessels because they had the shape of a circle, and the wall of the circle had endothelial cells, with blood cells in the circle. The circle was the cross-section of the vessel, and the vessel in this example intercepted the surface of the image. The blood vessel diameters were of the order of $25 \mu \mathrm{m}$.

The number of multinucleated cells was measured (mean $\pm \mathrm{sd}$; $n=12$ ) to be $41 \pm 3$ cells $/ \mathrm{mm}^{2}$ at 4 weeks. The blood vessel density was $52 \pm 4$ vessels $/ \mathrm{mm}^{2}$ in the 4 week implants. There was no significant difference between the BMSC recipient group and the control group regarding the densities of vessels and multinucleated cells $(p>0.05)$. At 6 weeks, the number of multinucleated cells decreased to $7 \pm 1$ cells $/ \mathrm{mm}^{2}$, and the blood vessel density decreased to $27 \pm 3$ vessels $/ \mathrm{mm}^{2}$. They represent a decrease by $82 \%$ and $49 \%$, respectively, compared to 4 weeks $(p<0.05)$.

Immunohistochemistry staining was performed (Fig. 5). In (A), the DAB-labeled collagen I (which stained collagen into a brown color) was present in between the $\mathrm{BCP}$ particles. This verified that the numerous clonal monocytoid cells in between the BCP particles deposited collagen I-rich osteoid which resembled bone or uncalcified bone matrix. The multinucleated cells adherent on the surfaces of the BCP particles in the implants were TRAP positive and stained a dark brown color (B), with arrows indicating multinucleated cells. The green dots in (B) are cell nucleus and the light brown areas are bone matrix or connective tissue. 

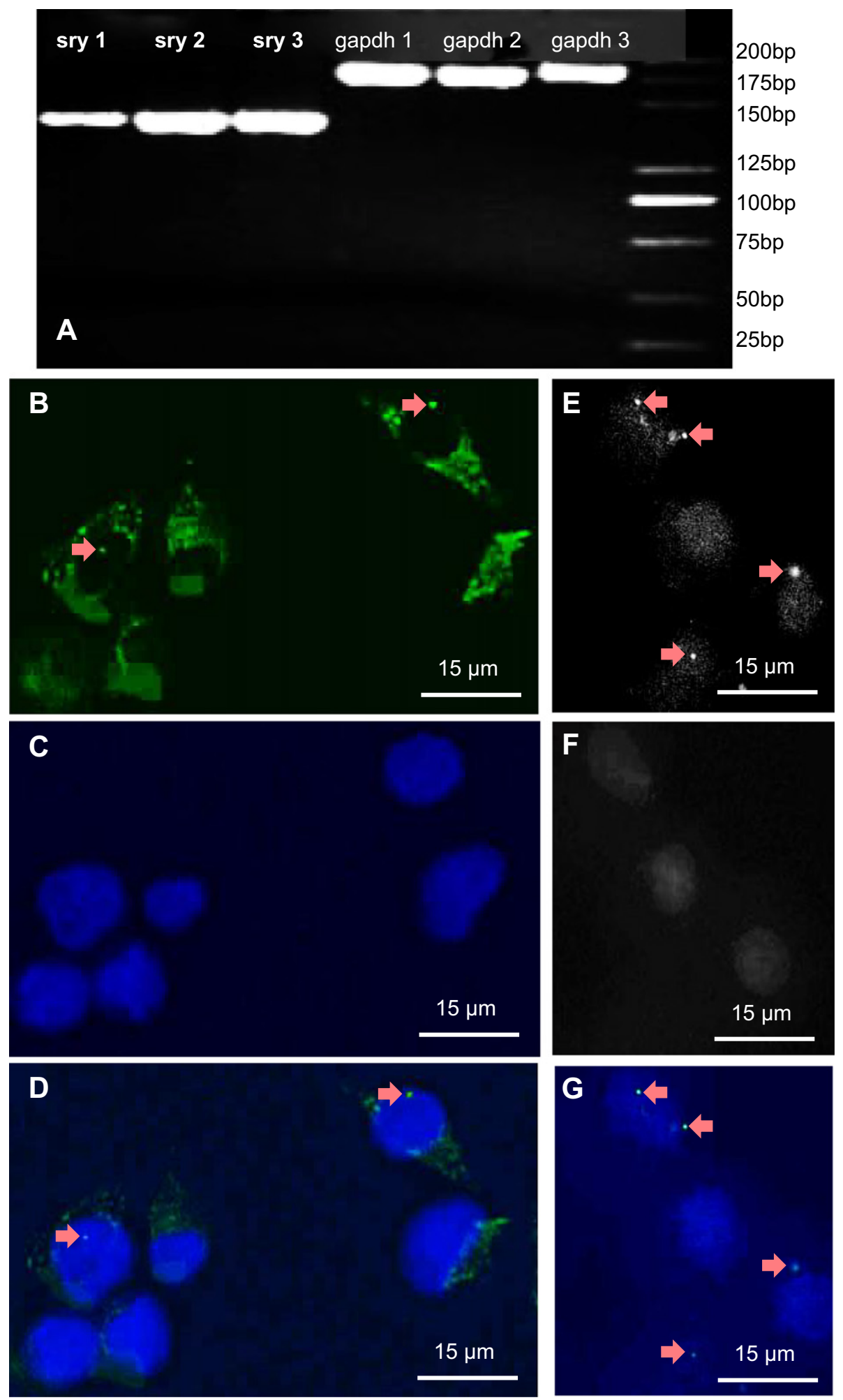

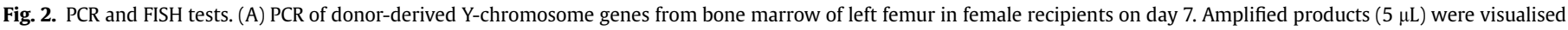

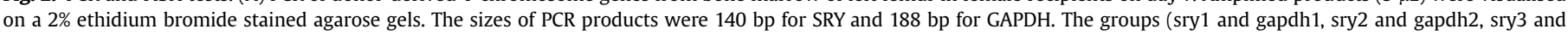

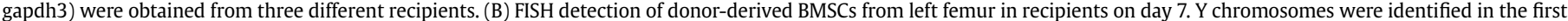

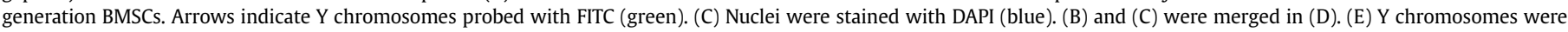

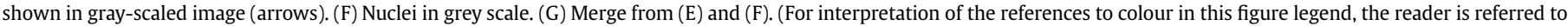
the web version of this article.) 

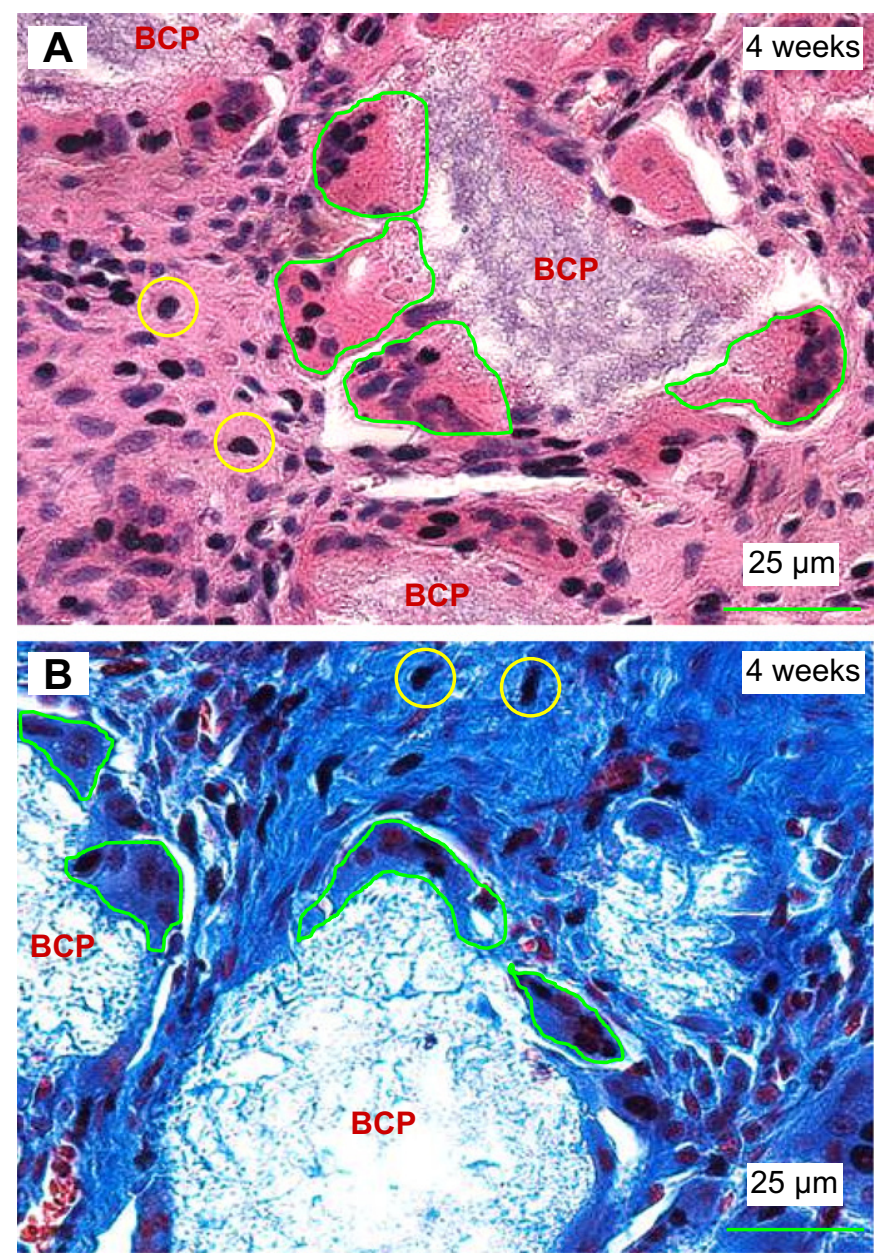

Fig. 3. Images of tissues retrieved at 4 weeks. The new bone matrix was stained red via $\mathrm{H} \& \mathrm{E}(\mathrm{A})$, and blue via Masson (B). Numerous clonal monocytoid cells (examples in circles) were seen in the middle regions of implants. Multinucleated cells, encircled by green lines, adhered to the $\mathrm{BCP}$ granules. The multinucleated cells had a typical osteoclast feature with a ruffled border facing the BCP particle. (For interpretation of the references to colour in this figure legend, the reader is referred to the web version of this article.)

Y chromosomes were detected in the harvested BCP implants from the BMSC recipient female dogs. SRY genes were shown in the implants harvested in two different time points (Fig. 6A). Meanwhile, numerous Y-positive nuclei were detected inside the monocytoid cells located in the middle regions of the implants harvested at 4 weeks for the BMSC recipient group (Fig. 6B). On the contrary, in the control group, no $\mathrm{Y}$ chromosomes were found (Fig. 6C).

Furthermore, single Y-positive nuclei were also detected inside the implants at 6 weeks (Fig. 7). In the surrounding osteoblasts in the new woven bone, $\mathrm{Y}$ chromosomes were probed with FITC (green), as indicated by arrows in (A). These Y chromosomes were located in the nuclei that were stained with DAPI into blue in (B). In $(C)$, the images of $(A)$ and $(B)$ were merged. In the middle regions of the BCP implants, Y chromosomes (arrows) were identified by FITC (Fig. 7D,E,F). Since FITC can non-specifically bind with cytoplasm, the cytoplasm also showed a green color (Fig. 7D, E, F).

For the BMSC recipient group, the measured density (mean $\pm \mathrm{sd} ; n=12$ ) of cell nuclei that were positive for Y chromosomes was $21 \pm 2$ cells $/ \mathrm{mm}^{2}$ in the 6 -week implants, significantly lower than $33 \pm 3$ cells $/ \mathrm{mm}^{2}$ at 4 weeks $(p<0.05)$. In comparison, the density of cell nuclei that were positive for $\mathrm{Y}$ chromosomes was 0 for the control group.
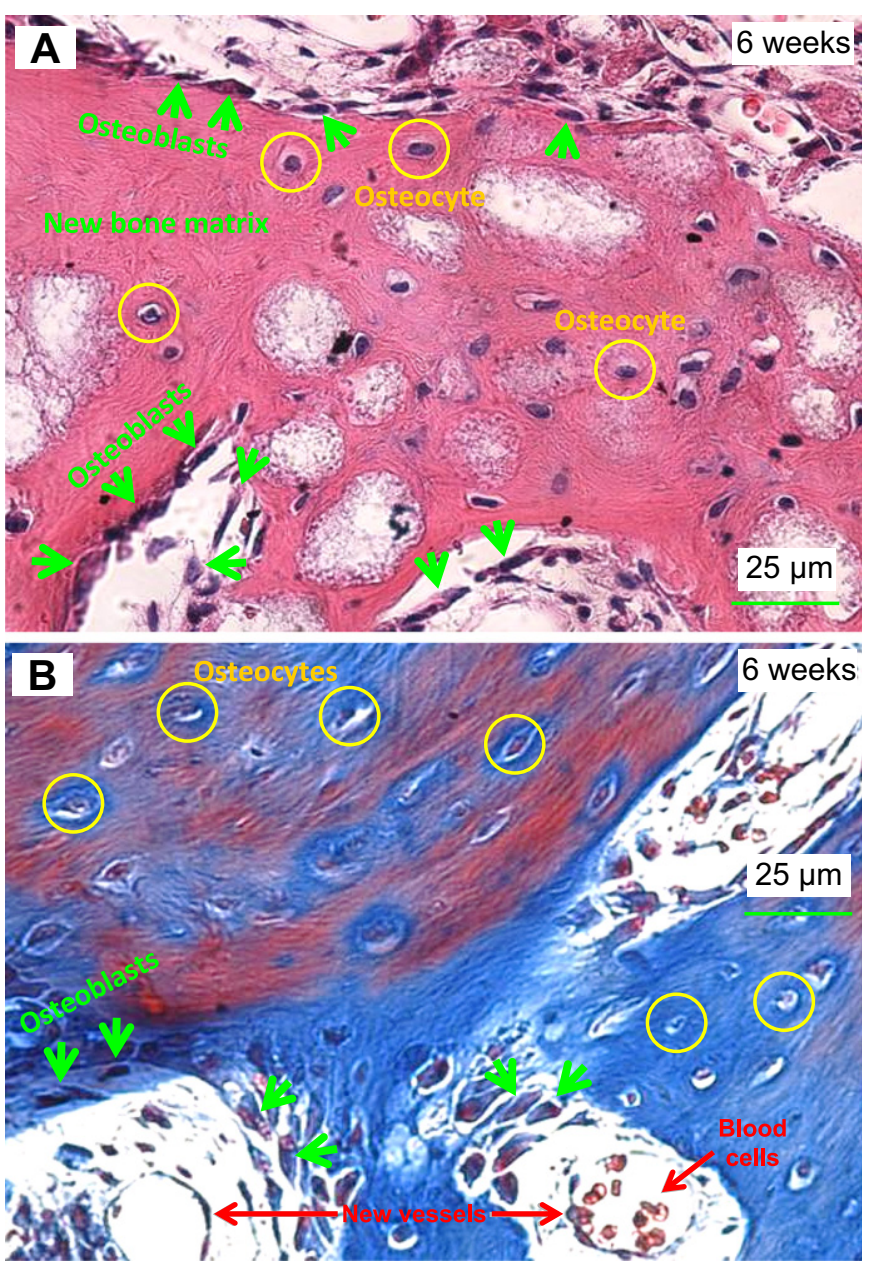

Fig. 4. Representative $H \& E(A)$ and Masson (B) images of tissues retrieved at 6 weeks Mineralized bone with osteocytes as well as active cubic osteoblasts were revealed. In (A), osteoblasts (arrows) were located at the boundary of the advancing new bone matrix. Osteocytes were embedded in the mineralized bone matrix. In (B), Masson stained bone matrix collagen into blue, and stained mineralization with mature bone into red. Hence, the Masson staining showed a mixture of blue and red regions in (B). New blood vessels and blood cells are indicated in the lower part of (B). (For interpretation of the references to colour in this figure legend, the reader is referred to the web version of this article.)

\section{Discussion}

This study demonstrated that BMSCs can be recruited from bone marrow through blood circulation to home to defects, and participate in ectopic bone formation via osteoinductive BCP in a canine model. Y chromosomes were detected in the BCP implants in the back muscles of female dogs that had received male BMSCs into their femur. The BCP implants exhibited an excellent osteoinductivity in vivo, inducing new bone formation in muscles without the delivery of growth factors. The use of ectopic bone to repair segmental bone defect as a therapy has received great interest among orthopaedic surgeons [48]. Nevertheless, the mechanism of bone formation induced by biomaterials is not well established. In particular, questions have been raised regarding the origins of stem cells, the relationship between biomaterial microstructure and the differentiation of stem cells, and the signals that trigger stem cells to differentiate into osteoblasts. Bone formation is an intricate and ordered cascade reaction between relevant stem cells and biomaterials in a continuously renewed internal environment, the procedure of which is regulated by growth factors [49]. Studies on growth factors have shown that BMPs play an important role in bone formation by integrating with homologous receptors of stem 

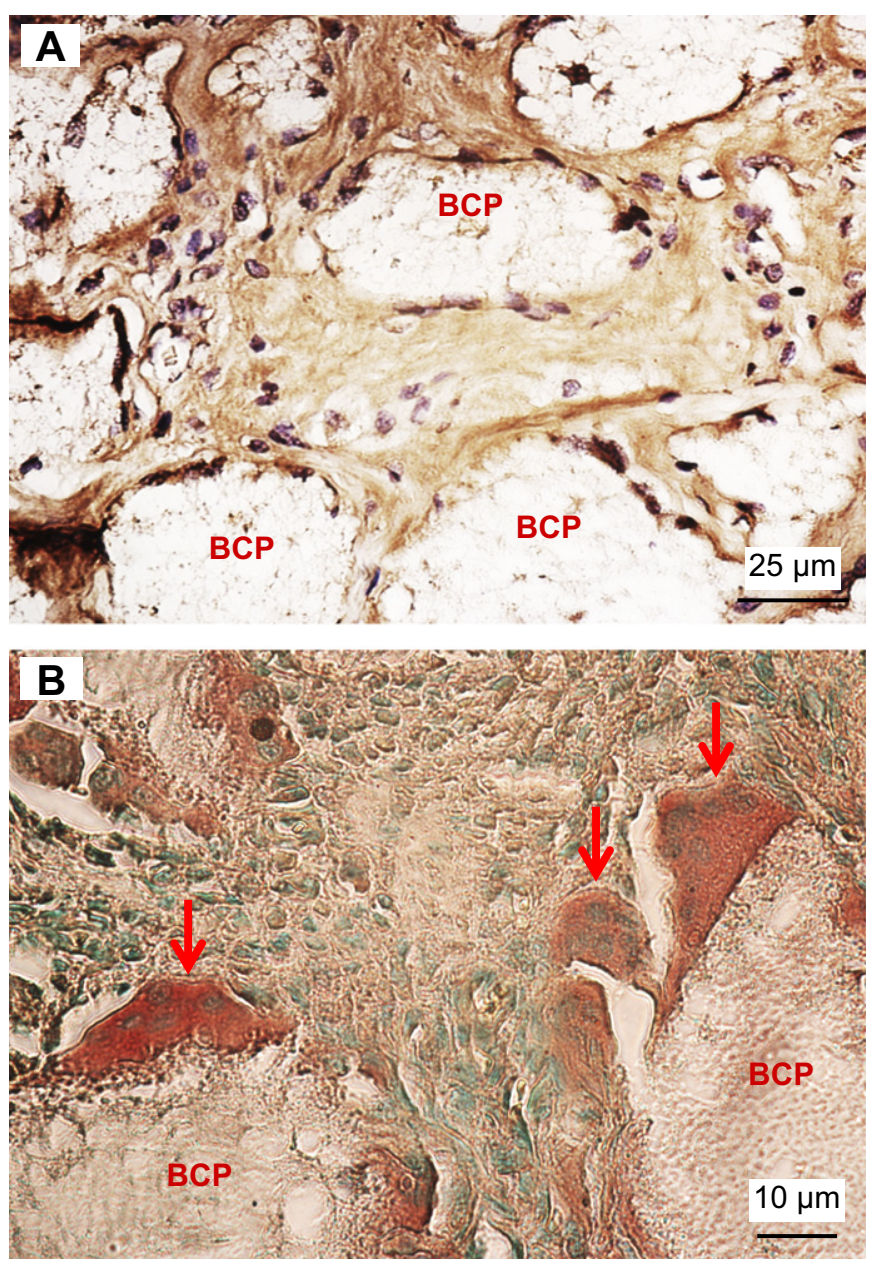

Fig. 5. Immunohistochemistry staining of collagen I and TRAP activity on $5 \mu \mathrm{m}$ thick deparaffinized sections of 4 weeks implants. (A) DAB-labeled collagen I (brown) was present inside the BCP implants. (B) TRAP positive multinucleated cells (dark brown) attached to the BCP granules. (For interpretation of the references to colour in this figure legend, the reader is referred to the web version of this article.)

cells to facilitate the expression of bone-related genes such as collagen I and alkaline phosphatase by signal transduction [50,51]. The results of the present study suggested that the BCP granules with a HA/ $\beta$-TCP ratio of $5 / 1$, with numerous micropores in the surfaces (Fig. 1B), were likely successful in adsorbing endogenous growth factors [30] from the body fluids in vivo, which was manifested by imparting an osteoinductivity to the BCP to achieve ectopic bone formation.

The existence of multinucleated cells at the biomaterial implant site (Fig. 3) indicated that the host body was resorbing the biomaterial. The density of multinucleated cells decreased from 4 to 6 weeks. This was likely because the amount of BCP materials decreased from 4 to 6 weeks, requiring less multinucleated cells to resorb. This was accompanied by an increase in the stained bone matrix area in the images, from approximately $42 \%$ at 4 weeks to $65 \%$ at 6 weeks. Furthermore, in the process of new bone formation, the formation of blood vessels is very important. The new bone at 4 weeks had a significantly higher blood vessel density than that at 6 weeks. This indicated that when the new bone started to mineralize and mature at 6 weeks, the density of blood vessels decreased, consistent with the fact that there are fewer vessels in mature bone than in immature bone [52]. In addition, the present study found that the density of Y-positive cell nuclei decreased with increasing time from 4 to 6 weeks. This is likely because the detected
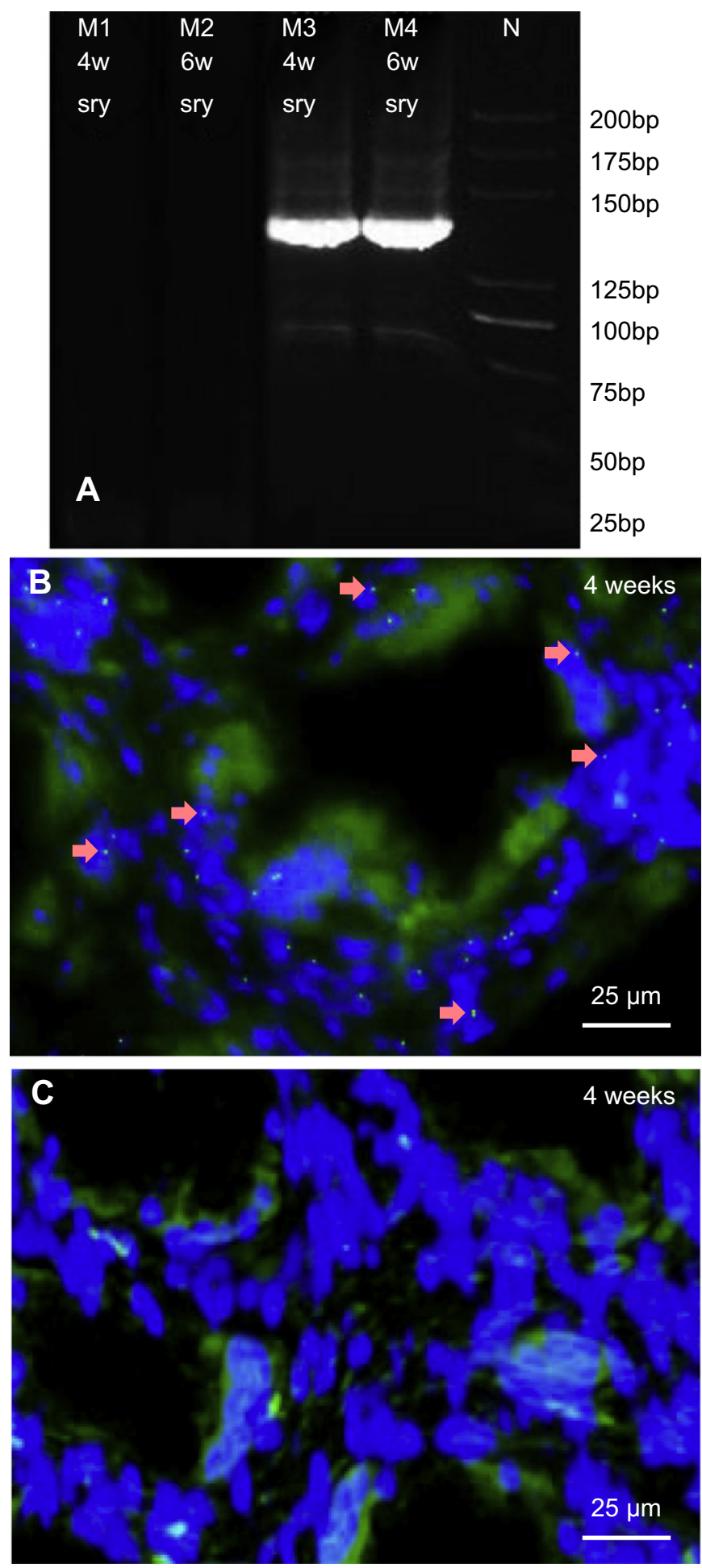

Fig. 6. (A) Detection of donor-derived Y-chromosome genes from implants harvested from animals. The size of SRY gene was $140 \mathrm{bp}$. SRY genes were detected in test group at both week 4 (M3) and week 6 (M4), inversely SRY gene was not seen at either week 4 (M1) or week 6 (M2) in control group. N represents ladder marker. (B, C) Identification of donor-derived BMSCs in 4 week implants via FISH. Y chromosomes (arrows) were detected in the implants harvested for the BMSC recipient group (A), but not in the implants harvested from the control group (B).

Y-positive cells first increased due to the recruitment and homing of these cells to the defect site, and then eventually decreased due to a possible decrease in self-renewal potential and dilution of the cells over time. 

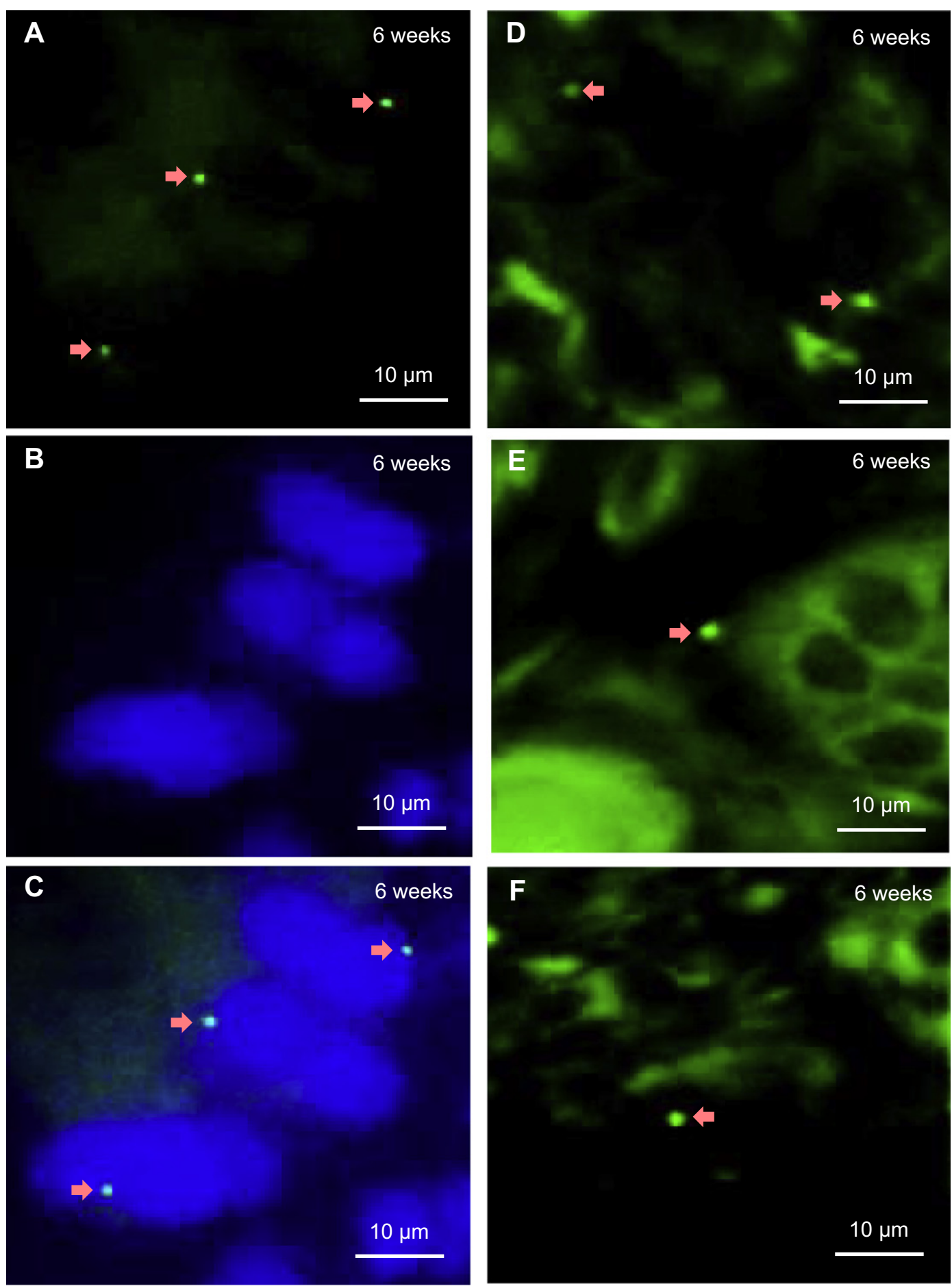

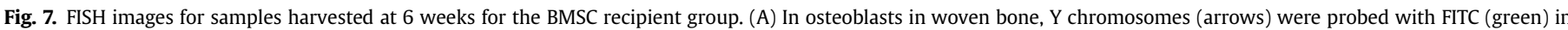

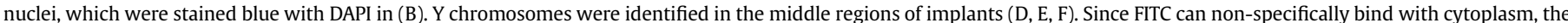

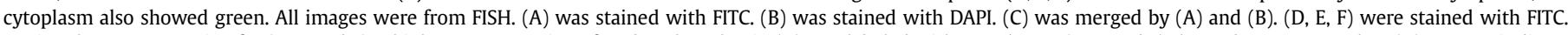

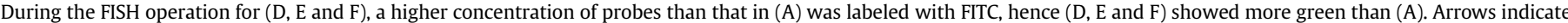
Y chromosomes. (For interpretation of the references to colour in this figure legend, the reader is referred to the web version of this article.)

BMSCs have been shown to possess the capability of multilineage differentiation in vitro $[2,4,22,33]$. Yet, in vivo, how they exercise autospecific function is not fully understood. Previous studies have reported that MSCs could be recruited to heal the impaired organs such as brain, skin and heart $[37,38,53]$. Based on these findings, the present study postulated that BMSCs may be able to migrate from the bone marrow to the muscle implant site to contribute to ectopic bone formation in vivo. This hypothesis was confirmed by the results of the present study in a large animal canine model. A previous study [54] found osteoblast progenitor cells (OPCs) in circulating blood contributed to ectopic bone formation in mice. However, ectopic bone formation via osteoinductive calcium phosphate ceramics without growth factor delivery was only observed in large animals, but not in rats and 
mice $[11,12]$. While it is postulated that MSCs from the host animal participate in ectopic bone formation via osteoinductive calcium phosphates, the present study provided the direct evidence that MSCs from the bone marrow cavity in femur migrated and homed to the muscle site and participated in ectopic bone formation via osteoinductive BCP. However, further study is needed to determine whether the BMSCs directly migrate into the biomaterial implant site to participate in bone formation, or first differentiate into osteoprogenitors in the bone marrow and then are recruited to the implanted site.

The canine model of sex-mismatched allogenic BMSCs transplantation in IO infusion was shown to be useful for tracking cell migration and participation in bone formation. By tracing donor cells from deviated sites of punctures, BMSCs were found to home to systemic bone marrow. This indicated that BMSCs constituted a complicated network in organism, by which they communicated with each other and transmitted signals. When an organism suffers from disease invasion, the bone marrow serves as the cell warehouse, and plays a central role by mobilizing pantosomatous BMSCs into blood circulation to join in the repair procedure. In addition, previous studies have shown the importance of recruiting BMSCs to defect sites for new bone formation [55,56]. Therefore, from the clinical perspective, triggering the signals that induce BMSCs immigration into circulation to increase the number of BMSCs in the lesion site provides an important cell-based therapy for bone fracture healing.

Regarding the experimental technology, the tracing of stem cells in bone remains a challenge, because non-specificity frequently occurs in sclerous tissues. Although transgenic-green fluorescent protein (GFP) based animal models have been employed, fluorescence signals easily extracted by ultraviolet rays in vitro will influence the experimental results. In the present study, Y chromosomes were selected as the labeling signal to monitor BMSC homing to the implant site. Using the model of sex-mismatched allogenic BMSC transplantation in dogs, this is the first direct evidence on a cellular level that MSCs as cell origin migrated from the bone marrow and participated in ectopic bone formation. In the transplantation process, radiation was conducted with the aim of creating chimerism space for the donor BMSCs [43]. This method provided a valid strategy for screening stem cells of sclerous tissue on a cellular level. Additionally, the present study found that the bone marrowderived nuclei were not only present in the osteogenic cell nuclei in the constructs, but were also present in the myocytes of the surrounding muscles at the implant sites (data not shown). These observations strengthen the theory that BMSCs were recruited to the damaged site to participate in muscle regeneration [53].

Histological analyses showed many monocytoid cells located in the middle regions of the reconstructs harvested at 4 weeks, while numerous multinucleated cells were distributed on the periphery of the BCP implant. When the time was increased to 6 weeks, woven bone was formed in the construct. The process of bone formation indicates the characteristic of intramembranous ossification. With regard to multinucleated cells, their presence was relevant to the degradation of the biomaterial implant which could then be replaced by new bone, as was shown in a previous study [8]. The TRAP-positive osteoclasts produce acid and promote the resorption and chemical dissolution of the BCP biomaterial. Meanwhile, at 4-6 weeks, the monocytoid cells appeared to have acquired osteoblastic properties and contributed to new bone formation, consistent with previous studies [57].

The present study demonstrated the recruitment of BMSCs to the implant site for ectopic bone formation in a canine model. These results indicate that local stimulation or systemic destruction will initiate the reaction of organism to induce the bone marrow to release stem cells by blood circulation in order to repair and recover the physiological functions. A previous study [58] found that MSCs can be mobilized into peripheral blood in the condition of hypoxia. When bioceramics are implanted into a muscle site, surgical injury necessarily destroys the local blood supply, which will cause an anoxic environment in the lesion site. Following this process, BMSCs are mobilized and recruited to the biomaterial site from the remote bone marrow sites. This delivery system is similar to the recruitment of BMSCs in fracture healing in an osseous site [59], although the present study showed MSC recruitment from the bone marrow to a muscle BCP site. Calcium phosphate bioceramics are known to be osteoconductive, and many previous studies demonstrated that calcium phosphate bioceramics, combined with MSCs $[8,9]$ and/or growth factor [10] could induce ectopic bone formation. Furthermore, several studies showed that calcium phosphate bioceramics can also be osteoinductive, with several reports showing the application of calcium phosphate alone in ectopic bone formation [11-13]. However, the mechanism of osteoinductive calcium phosphate bioceramics is not clear. The present study provided direct evidence in a dog model that MSCs from the bone marrow migrated to the defect site and contributed to the ectopic bone formation induced by calcium phosphate bioceramic. Further study is also needed to investigate the co-participation of stem cells from bone marrow, neighboring muscle, and adipose tissues next to the implanted BCP, and their respective contribution to new bone formation.

\section{Conclusion}

This study showed that MSCs from bone marrow migrated via blood circulation to defect sites with ectopic bone formation via osteoinductive bioceramics in a canine model. The donor MSCs in the bone marrow of recipient dogs survived and acquired stable chimerism. The sex-mismatched allogeneic BMSC transplantation model was suitable for tracing stem cell migration and cell origin in regeneration of sclerous tissues. Additionally, microporous BCP implant was demonstrated to be osteoinductive in dog muscles to form new bone. These results provided the direct proof that MSCs in animal's bone marrow home to non-osseous sites to participate in ectopic bone formation induced by osteoinductive bioceramics. The ability of such implants to recruit distant MSCs and induce osteogenic differentiation and bone formation is promising for applications in regenerative medicine.

\section{Acknowledgements}

The authors would like to thank Dr. Jan de Bore in Department of Tissue Regeneration, BMTI, University of Twente, The Netherlands, for his help in design the experiment. We thank Xiaoyu Li, Min Zhou, Yurong Liu, Xiaoqin Yang, and Yunfeng Li for experimental assistance. We also thank the technical assistance from the Key Laboratory of Transplant Engineering and Immunology of Ministry of Health, West China Hospital, Sichuan University. This work was funded by the National Science foundation of China (NSFC30672337 and NSFC-30970728 to CB) and NIH R01 DE14190 (to HX).

\section{References}

[1] Mikos AG, Herring SW, Ochareon P, Elisseeff J, Lu HH, Kandel R, et al. Engineering complex tissues. Tissue Eng 2006;12:3307-39.

[2] Mao JJ, Giannobile WV, Helms JA, Hollister SJ, Krebsbach PH, Longaker MT, et al. Craniofacial tissue engineering by stem cells. J Dent Res 2006;85: 966-79.

[3] Kaigler D, Krebsbach PH, Wang Z, West ER, Horger K, Mooney DJ. Transplanted endothelial cells enhance orthotopic bone regeneration. J Dent Res 2006;85: $633-7$. 
[4] Johnson PC, Mikos AG, Fisher JP, Jansen JA. Strategic directions in tissue engineering. Tissue Eng 2007;13:2827-37.

[5] Silva GA, Coutinho OP, Ducheyne P, Reis RL. Materials in particulate form for tissue engineering, Part 2: applications in bone (review). J Tissue Eng Regen Med 2007;1:97-109.

[6] Bohner M. Design of ceramic-based cements and putties for bone graft substitution. Eur Cell Mater 2010;20:1-12.

[7] United States Bone and Joint Decade (USBJD) 2002-2011. The burden of musculoskeletal diseases in the United States. Rosemont, IL: American Academy of Orthopaedic Surgeons; 2008. Foreword.

[8] Trojani C, Boukhechba F, Scimeca JC, Vandenbos F, Michiels JF, Daculsi G, et al. Ectopic bone formation using an injectable biphasic calcium phosphate/SiHPMC hydrogel composite loaded with undifferentiated bone marrow stromal cells. Biomaterials 2006;27:3256-64.

[9] Kruyt MC, Dhert WJ, Oner FC, van BCA, Verbout AJ, de Bruijn JD. Analysis of ectopic and orthotopic bone formation in cell-based tissue-engineered constructs in goats. Biomaterials 2007;28:1798-805

[10] Wang L, Huang Y, Pan K, Jiang X, Liu C. Osteogenic responses to different concentrations/ratios of BMP-2 and bFGF in bone formation. Ann Biomed Eng 2010;38:77-87.

[11] Ripamonti U. Osteoinduction in porous hydroxyapatite implanted in heterotopic sites of different animal models. Biomaterials 1996;17:31-5.

[12] Le Nihouannen D, Daculsi G, Saffarzadeh A, Gauthier O, Delplace S, Pilet P, et al. Ectopic bone formation by microporous calcium phosphate ceramic particles in sheep muscles. Bone 2005;36:1086-93.

[13] Kondo N, Ogose A, Tokunaga K, Umezu H, Arai K, Kudo N, et al. Osteoinduction with highly purified beta-tricalcium phosphate in dog dorsal muscles and the proliferation of osteoclasts before heterotopic bone formation. Biomaterials 2006;27:4419-27.

[14] Habibovic P, Gbureck U, Doillon CJ, Bassett DC, van Blitterswijk CA, Barralet JE. Osteoconduction and osteoinduction of low-temperature 3D printed bioceramic implants. Biomaterials 2008;29:944-53.

[15] Ducheyne P, Qiu Q. Bioactive ceramics: the effect of surface reactivity on bone formation and bone cell function. Biomaterials 1999;20:2287-303.

[16] Chow LC. Calcium phosphate cements: chemistry, properties, and applications. Mat Res Symp Proc 2000;599:27-37.

[17] Pilliar RM, Filiaggi MJ, Wells JD, Grynpas MD, Kandel RA. Porous calcium polyphosphate scaffolds for bone substitute applications - in vitro characterization. Biomaterials 2001;22:963-72.

[18] Ginebra MP, Rilliard A, Fernández E, Elvira C, Román JS, Planell JA. Mechanical and rheological improvement of a calcium phosphate cement by the addition of a polymeric drug. J Biomed Mater Res 2001;57:113-8.

[19] Barralet JE, Gaunt T, Wright AJ, Gibson IR, Knowles JC. Effect of porosity reduction by compaction on compressive strength and microstructure of calcium phosphate cement. J Biomed Mater Res B Appl Biomater 2002;63:1-9.

[20] Xu HHK, Simon Jr CG. Fast setting calcium phosphate-chitosan scaffold: mechanical properties and biocompatibility. Biomaterials 2005;26:1337-48.

[21] Deville S, Saiz E, Nalla RK, Tomsia AP. Freezing as a path to build complex composites. Science 2006;311:515-8.

[22] Bohner M, Baroud G. Injectability of calcium phosphate pastes. Biomaterials 2005;26:1553-63.

[23] Reilly GC, Radin S, Chen AT, Ducheyne P. Differential alkaline phosphatase responses of rat and human bone marrow derived mesenchymal stem cells to 45S5 bioactive glass. Biomaterials 2007;28:4091-7.

[24] Russias J, Saiz E, Deville S, Gryn K, Liu G, Nalla RK, et al. Fabrication and in vitro characterization of three-dimensional organic/inorganic scaffolds by robocasting. J Biomed Mater Res A 2007;83:434-45.

[25] Habibovic P, Yuan H, van der Valk CM, Meijer G, van Blitterswijk CA, de Groot K. 3D microenvironment as essential element for osteoinduction by biomaterials. Biomaterials 2005;26:3565-75.

[26] Winter GD, Simpson BJ. Heterotopic bone formed in a synthetic sponge in the skin of young pigs. Nature 1969;223:88-90.

[27] Yao J, Li X, Bao C, Fan H, Zhang X, Chen Z. A novel technique to reconstruct a boxlike bone defect in the mandible and support dental implants with in vivo tissue engineered bone. J Biomed Mater Res B Appl Biomater 2009;91: 805-12.

[28] Yuan H, Fernandes H, Habibovic P, de Boer J, Barradas AM, de Ruiter A, et al. Osteoinductive ceramics as a synthetic alternative to autologous bone grafting. Proc Natl Acad Sci U S A 2010;107:13614-9.

[29] Yuan H, Yang Z, Li Y, Zhang X, De Bruijn JD, De Groot K. Osteoinduction by calcium phosphate biomaterials. J Mater Sci Mater Med 1998;9:723-6.

[30] De Groot J. Carriers that concentrate native bone morphogenetic protein in vivo. Tissue Eng 1998;4:337-41.

[31] Mao JJ, Vunjak-Novakovic G, Mikos AG, Atala A. Regenerative medicine: Translational approaches and tissue engineering. Boston, MA: Artech House; 2007.

[32] Jansen JA, Vehof JWM, Ruhe PQ Kroeze-Deutman H, Kuboki Y, Takita H, et al. Growth factor-loaded scaffolds for bone engineering. J Control Release 2005; 101:127-36

[33] Benoit DSW, Nuttelman CR, Collins SD, Anseth KS. Synthesis and characterization of a fluvastatin-releasing hydrogel delivery system to modulate hMSC differentiation and function for bone regeneration. Biomaterials 2006;27: 6102-10.
[34] Morgan AW, Roskov KE, Lin-Gibson S, Kaplan DL, Becker ML, Simon Jr CG. Characterization and optimization of RGD-containing silk blends to support osteoblastic differentiation. Biomaterials 2008;29:2556-63.

[35] Bao C, Chen W, Weir MD, Thein-Han W, Xu HHK. Effects of electrospun submicron fibers in calcium phosphate cement scaffold on mechanical properties and osteogenic differentiation of umbilical cord stem cells. Acta Biomater 2011;7:4037-44.

[36] Chen W, Zhou H, Tang M, Weir MD, Bao C, Xu HHK. Gas-foaming calcium phosphate cement scaffold encapsulating human umbilical cord stem cells. Tissue Eng A 2012;18:816-27.

[37] François S, Bensidhoum M, Mouiseddine M, Mazurier C, Allenet B, Semont A et al. Local irradiation not only induces homing of human mesenchymal stem cells at exposed sites but promotes their widespread engraftment to multiple organs: a study of their quantitative distribution after irradiation damage. Stem Cells 2006;24:1020-9.

[38] Qu C, Mahmood A, Lu D, Goussev A, Xiong Y, Chopp M. Treatment of traumatic brain injury in mice with marrow stromal cells. Brain Res 2008; 1208:234-9.

[39] Burnett RC, Francisco LV, DeRose SA, Storb R, Ostrander EA. Identification and characterization of a highly polymorphic microsatellite marker within the canine MHC class Iregion. Mamm Genome 1995;6:684-5.

[40] Wagner JL, Burnett RC, DeRose SA, Francisco LV, Storb R, Ostrander EA. Histocompatibility testing of dog families with highly polymorphic microsatellite markers. Transplantation 1996;62:876-7.

[41] Yuan J, Cui L, Zhang WJ, Liu W, Gao YL. Repair of canine mandibular bone defects with bone marrow stromal cells and porous $\beta$-tricalcium phosphate. Biomaterials 2007;28:1005-13.

[42] Tang H, Xu ZF, Qin X, Wu B, Wu LH, Zhao XW, et al. Chest wall reconstruction in a canine model using polydioxanone mesh, demineralized bone matrix and bone marrow stromal cells. Biomaterials 2009;30:3224-33.

[43] Storb R, Yu C, Barnett T, Wagner JL, Deeg HJ, Nash RA, et al. Mixed hematopoietic chimerism in dog leukocyte antigen- identical littermate dogs given lymph node irradiation before and pharmacologic immunosuppression after marrow transplantation. Blood 1999;94:1131-6.

[44] Niemeyer GP, Welch JA, Tillson M, Brawner W, Rynders P, Goodman S, et al. Renal allograft tolerance in DLA-identical and haploidentical dogs after nonmyeloablative conditioning and transient immunosuppression with cyclosporine and mycophenolate mofetil. Transplant Proc 2005;37: 4579-86.

[45] Feng Q, Chow PK, Frassoni F, Phua CM, Tan PK, Prasath A, et al. Nonhuman primate allogeneic hematopoietic stem cell transplantation by intraosseus vs intraosseous injection: engraftment, donor cell distribution, and mechanistic basis. Exp Hematol 2008;36:1556-66.

[46] Meyers WVN, Schlafer DBI, Lovell BR, Keyzner A. Sry-negative XX sex reversal in pure-bred dogs. Mol Reprod Dev 1999;53:266-73.

[47] Fiegler H, Knabel M, Franz M, Kolb HJ, Just U. Determination of donor-type chimerism using a semi-quantitative PCR-based method in canine model for bone marrow transplantation. Vet Immunol Immunopathol 2002;84:61-70.

[48] Service RF. Tissue engineering: technique uses body as 'bioreactor' to grow new bone. Science 2005;309:683.

[49] Giraud Guille MM, Mosser G, Helary C, Eglin D. Bone matrix like assemblies of collagen: from liquid crystals to gels and biomimetic materials. Micron 2005; 36:602-8.

[50] Luk KDK, Chen Y, Cheung KMC, Kung HF, Lu WW, Leong JC. Adeno-associated virus-mediated bone morphogenetic protein-4 gene therapy for in vivo bone formation. Biochem Biophys Res Commun 2003;308:636-45.

[51] Wang C, Duan Y, Markovic B, Barbara J, Howlett CR, Zhang X, et al. Phenotypic expression of bone-related genes in osteoblasts grown on calcium phosphate ceramics with different phase compositions. Biomaterials 2004;25: 2507-14.

[52] Barou O, Mekraldi S, Vico L, Boivin G, Alexandre C, Lafage-Proust MH Relationships between trabecular bone remodeling and bone vascularization: a quantitative study. Bone 2002;30:604-12.

[53] Bittner RE, Schöfer C, Weipoltshammer K, Ivanova S, Streubel B, Hauser E, et al. Recruitment of bone-marrow-derived cells by skeletal and cardiac muscle in adult dystrophic mdx mice. Anat Embryol 1999;199:391-6.

[54] Otsuru S, Tamai K, Yamazaki T, Yoshikawa H, Kaneda Y. Bone marrow-derived osteoblast progenitor cells in circulating blood contribute to ectopic bone formation in mice. Biochem Biophys Res Commun 2007;354:453-8.

[55] Mauney JR, Jaquiery C, Volloch V, Heberer M, Martin I, Kaplan DL. In vitro and in vivo evaluation of differentially demineralized cancellous bone scaffolds combined with human bone marrow stromal cells for tissue engineering. Biomaterials 2005;26:3173-85.

[56] Meinel L, Fajardo R, Hofmann S, Langer R, Chen J, Snyder B, et al. Silk implants for the healing of critical size bone defects. Bone 2005;37:688-98.

[57] Zerbo IR, Bronckers AL, de Lange G, Burger EH. Localisation of osteogenic and osteoclastic cells in porous beta-tricalcium phosphate particles used for human maxillary sinus floor elevation. Biomaterials 2005;26:1445-51.

[58] Rochefort GY, Delorme B, Lopez A, Hérault O, Bonnet P, Charbord P, et al Multipotential mesenchymal stem cells are mobilized into peripheral blood by hypoxia. Stem Cells 2006;24:2202-8

[59] Shirley D, Marsh D, Jordan G, McQuaid S, Li G. Systemic recruitment of osteoblastic cells in fracture healing. J Orthop Res 2005;23:1013-21. 